\title{
Palmito de pupunha (Bactris gasipaes Kunth.) composição mineral e cinética de enzimas oxidativas
}

\author{
Heart of palm (Bactris gasipaes Kunth.): mineral composition and kinetics of oxidative enzymes
}

Nathália Ottoboni GALDINO ${ }^{1}$, Edmar CLEMENTE $^{1 *}$

\section{Resumo}

A análise da presença de enzimas oxidativas como a peroxidase (POD) e a polifenoloxidase (PPO) e o controle da atividade destas enzimas são importantes na preservação e no processamento de alimentos. Este trabalho teve por objetivo determinar a atividade enzimática da polifenoloxidase (PPO) e da peroxidase (POD) do palmito de pupunha, bem como avaliar o comportamento destas enzimas frente ao tratamento térmico e assim calcular a cinética de inativação térmica das mesmas para suas porções termorresistente e termolábil. Para a extração de peroxidase (POD) e polifenoloxidase (PPO) de palmito, utilizou-se solução tampão fosfato de sódio $100 \mathrm{mM}$ com diferentes pHs $(5,5 ; 6,0 ; 6,5$ e 7,0). O melhor $\mathrm{pH}$ de extração da POD foi 5,5 e da PPO, 6,5. Estes extratos foram tratados em diferentes temperaturas $\left(65,70,75\right.$ e $\left.80^{\circ} \mathrm{C}\right)$ por períodos de 1 a 10 minutos. A POD e a PPO sofreram um decréscimo de 70 e $80 \%$, respectivamente, em relação às suas atividades iniciais. As energias de ativação, nas temperaturas estudadas, para a porção termolábil e termorresistente da peroxidase

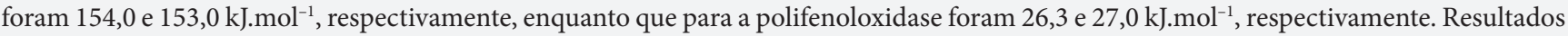
apresentaram valores que estão dentro da faixa de energia de ativação reportada para o processo de inativação térmica de enzimas.

Palavras-chave: peroxidase; polifenoloxidase; palmito; pupunha.

\begin{abstract}
Analysis of oxidative enzymes such as peroxidase (POD) and polyphenoloxidase (PPO) and the control of the activity of these enzymes are important in food preservation and also in food processing. The aim of this work was to determine polyphenoloxidase (PPO) and peroxidase (POD) enzymatic activity in heart of palm, as well as to evaluate enzyme behavior during thermal treatment, determining the kinetics of thermal inactivation of the heat resistant and heat labile portions. For the extraction of peroxidase (POD) and polyphenoloxidase (PPO) from the heart of palm solution, $100 \mathrm{mM}$ sodium phosphate buffer with different $\mathrm{pH}$ values $(5.5 ; 6.0 ; 6.5$ and 7.0$)$ was used. Optimum $\mathrm{pH}$ for extraction was 5.5 and 6.5, for POD and PPO, respectively. These extracts were treated at different temperatures $\left(65,70,75\right.$ and $\left.80{ }^{\circ} \mathrm{C}\right)$ for periods of 1 to 10 minutes. Decreases in POD and PPO activities of around 70 and $80 \%$, respectively, in relation to their initial activities were observed. The activation energies, in the temperatures studied, for the heat labile and resistant portions of peroxidase were 154.0 and $153.0 \mathrm{~kJ} \cdot \mathrm{mol}^{-1}$, and of polyphenoloxidase, 26.3 and $27.0 \mathrm{~kJ} . \mathrm{mol}^{-1}$, respectively. The results showed values that are in the range for activation energy reported for the thermal inactivation process of enzymes.
\end{abstract}

Keywords: peroxidase; polyphenoloxidase; heart of palm.

\section{Introdução}

O Brasil é o primeiro produtor mundial de palmito, com produção estimada em 180.000 toneladas anuais, em sua maioria, proveniente de juçara ou palmiteiro (Euterpe edulis) e açaí (Euterpe oleraceae). Entre 1992 e 1995, o mercado consumidor foi de 130,4 milhões de dólares. As maiores limitações ao incremento do consumo do palmito industrializado são: a) o palmito em conserva disponível no varejo é muito irregular quanto à espessura, podendo ser encontrados toletes finos e grossos na mesma embalagem; b) a irregularidade na textura variando do excessivamente macio ao fibroso; e c) falta de controle na industrialização, com risco de contaminação do produto pela bactéria Clostridium botulinum, causadora do botulismo, danoso à saúde humana (BONACINI, 1999).

No mercado brasileiro, o palmito é comercializado na forma de talos (cilindros e toletes) com diâmetro entre 1,5 e $4 \mathrm{~cm}$
(TONET; FERREIRA; OTOBONI, 1999). As principais formas de comercialização do palmito são in natura e envasado ou enlatado (conserva).

O palmito de pupunha, de modo diverso dos palmitos do gênero Euterpe, pode ser comercializado sem o processamento necessário aos outros por possuir níveis mais baixos de duas enzimas que oxidam palmitos do gênero Euterpe, bem como menos taninos e mais açúcares que estes (FERREIRA et al., 1982a; b).

A pupunheira (Bactris gasipaes Kunth) é uma palmeira de clima tropical em que todas as partes podem ser aproveitadas, embora sejam mais importantes economicamente os frutos e o palmito (CLEMENT; BOVI, 1999). A importância dessa palmeira cresceu consideravelmente no Brasil, por ser uma

Recebido para publicação em 8/2/2007

Aceito para publicação em 10/1/2008 (002290)

Laboratório de Bioquímica de Alimentos, Departamento de Química, Universidade Estadual de Maringá - UEM, Av. Colombo, 5790, CEP 87020-900,

Maringá - PR,Brasil,E-mail:eclemente@uem.br; nathaliaottoboni@ig.com.br

${ }^{*}$ A quem a correspondência deve ser enviada 
excelente alternativa para cultivo sustentável do palmito em agricultura de pequeno porte.

A pupunheira apresenta uma série de vantagens para produção de palmito em relação às outras palmeiras nativas como o açaí (Euterpe oleraceae Martius) e a juçara (Euterpe edulis Martius), que são exploradas de forma extrativista e por isso apresentam restrições legais e risco de extinção (CHAIMSOHN, 2000; CHAIMSOHN, 2002).

O palmito in natura é o palmito bruto colhido no campo e apresenta de 3 a 4 bainhas de proteção ao redor da parte comestível e comprimento de 45 a $90 \mathrm{~cm}$. O palmito orgânico, sem agrotóxicos e sem fertilizantes químicos está sendo vendido no sudeste a 10 reais a peça. Sua duração é de 3 a 5 dias, que poderá ser prolongada se o produto for resfriado e se as pontas cortadas forem tratadas com cera ou outro produto antitranspirante e protetor contra fungos e bactérias. Possui aparência e cor atrativas, sabor suave, levemente adocicado, recomendado para o preparo do palmito assado na brasa.

O palmito fresco ou minimamente processado é definido como o palmito comestível, após a extração das bainhas frescas de proteção; sempre haverá porções de estipe tenro e folhas tenras, ambos frescos (KAPP et al., 2003). Os três estilos ou cortes (estipe tenro, palmito e folhas tenras) poderão ser oferecidos ao consumidor em bandejas diferentes, aplicando estes produtos a receitas culinárias também diferentes. Sugestões de receitas simples devem acompanhar o produto. Os toletes podem ser cortados em comprimento de 9 a $10 \mathrm{~cm}$ ou mais ou menos compridos. Estes toletes poderão ser tratados em soluções salinas (RAUPP, 2004; SOARES, 1997) ou cloradas (BELEGARD et al., 2005; JIMENEZ, 1992) para garantir sua assepsia antes de serem embalados. Os toletes poderão ser acondicionados em sacos plásticos ou em bandejas de isopor cobertos com filme plástico transparente. $\mathrm{O}$ palmito poderá ser conservado por 10 a 14 dias sob refrigeração $\left(10^{\circ} \mathrm{C}\right)$ e no escuro (CLEMENT; MORA URPÍ, 1987), o que é suficiente para comercialização perto do local de produção. Diversos produtores do sudeste estão colocando este tipo de produto nos supermercados. As bandejas são expostas, sob refrigeração e no claro, com tempo de prateleira de, no máximo, 5 dias. Este produto está disponível no Rio de Janeiro, São Paulo e em Honolulu e já possui demanda em Chicago, Washington, Nova York e Boston (CLEMENT; BOVI, 1999). Esta demanda será fácil de ser criada nos maiores supermercados do Brasil, pois o produto fresco conserva todo o atrativo do produto in natura e não é tão trabalhoso. $\mathrm{Na}$ cozinha, o palmito fresco pode ser cortado e servido, sem preparo prévio, em saladas, ou também frito, assado ou cozido em qualquer combinação e com qualquer acompanhamento. Os diferentes produtos atraem diferentes grupos étnicos. No Havaí, os europeus gostaram mais do palmito, enquanto os tailandeses e chineses gostaram mais do estipe tenro (CLEMENT; BOVI, 1999).

O estado do Paraná recentemente começou a produzir palmito de pupunha e a qualidade do produto, quanto ao processamento, é muito importante para sua comercialização. A análise da presença de enzimas oxidativas como a peroxidase e a polifenoloxidase é de muita importância, pois estas enzimas são oxirredutases capazes de catalisar um grande número de re- ações de oxidação em plantas, usando também em alguns casos, oxigênio e hidrogênio como aceptor (McLELLAN; ROBINSON, 1984). O controle da atividade de peroxidase e polifenoloxidase é importante na preservação e no processamento de alimentos, pois podem promover escurecimento em frutas e vegetais e de seus produtos industrializados. Estas enzimas podem participar de um grande número de reações oxidativas, causando mudança de cor, degradação da clorofila ou auximas, oxidação de fenóis, oxidação do ácido indol acético, biossíntese da lignina, e muitos destes fatores também podem ser associados com o "flavour", a cor, a textura e as qualidades nutricionais dos alimentos (CLEMENTE; PASTORE, 1998).

Dessa forma, o objetivo desse trabalho foi determinar a atividade enzimática da polifenoloxidase (PPO) e da peroxidase (POD), bem como avaliar o comportamento destas frente ao tratamento térmico e assim calcular a cinética de inativação térmica das mesmas para suas porções termorresistente e termolábil.

\section{Material e métodos}

Os palmitos foram coletados na Fazenda Experimental da Universidade, os quais foram transportados no mesmo dia para o Laboratório de Bioquímica de Alimentos/DQI-UEM, onde os toletes foram descascados, higienizados e preparados para a extração das frações enzimáticas.

\subsection{Avaliação do pH para extração de POD e PPO}

Este teste teve como objetivo determinar o melhor $\mathrm{pH}$ de extração das enzimas peroxidase (POD) e polifenoloxidase (PPO). O teste consistiu na extração da peroxidase e também da polifenoloxidase por tampão fosfato de sódio $(100 \mathrm{mM}) \mathrm{e}$ pHs 5,5; 6,0; 6,5 e 7,0. As atividades enzimáticas para POD e PPO foram determinadas segundo os métodos descritos por Clemente (1998) e Siddiq et al. (1992), respectivamente.

\subsection{Extração da peroxidase (POD) $e$ da polifenoloxidase (PPO)}

Após definição do melhor $\mathrm{pH}$ de extração, novos extratos brutos de peroxidase e polifenoloxidase foram preparados. Para isto, foram pesados cerca de $30.000 \mathrm{~g}$ de palmito, sendo este homogeneizado em liquidificador com cerca de $60 \mathrm{~mL}$ de solução tampão fosfato de sódio $100 \mathrm{mM}$ gelada, com pH 5,5 para peroxidase e 6,5 para polifenoloxidase. Após homogeneização, as amostras foram filtradas em tecido de algodão, os filtrados foram centrifugados a 17.000 g por 20 minutos, a $4{ }^{\circ} \mathrm{C}$. Posteriormente, os sobrenadantes contendo $\mathrm{PPO}$ e POD de palmito de pupunha foram congelados a $-18^{\circ} \mathrm{C}$.

\subsection{Atividade enzimática da POD e PPO}

A atividade enzimática de POD foi determinada pelo método descrito por Clemente (1998), utilizando um espectrofotômetro $\operatorname{com} \lambda=460 \mathrm{~nm}$. Para a reação misturou-se $0,2 \mathrm{~mL}$ do extrato enzimático concentrado com $2,7 \mathrm{~mL}$ de solução de água oxigenada $0,1 \%$ em tampão fosfato de sódio (100 mM e pH 5,5), e finalmente adicionou-se $0,1 \mathrm{~mL}$ de solução de o-dianisidina $1 \%$ 
em etanol. Uma unidade de atividade de POD foi definida como o aumento de uma unidade de absorbância por minuto. $\mathrm{mL}^{-1}$ de amostra. A atividade da PPO foi realizada de acordo com o método descrito por Siddiq et al. (1992).

\subsection{Determinação do teor de minerais e proteína bruta}

A determinação e a quantificação dos minerais $\mathrm{Mg}, \mathrm{Ca}, \mathrm{K}, \mathrm{P}$, $\mathrm{Fe}, \mathrm{Cu}, \mathrm{Mn}, \mathrm{Zn}$ e Na foram realizadas utilizando espectroscopia da absorção atômica por chama, onde o oxidante e o combustível utilizados na produção da chama foram o ar e o acetileno, respectivamente. $\mathrm{O}$ teor de proteína bruta, determinado através da quantidade de nitrogênio total, foi encontrado utilizando o método Semi-Micro Kjeldahl.

\subsection{Tratamento térmico da POD e PPO}

O tratamento térmico foi realizado em quatro temperaturas $\left(65,70,75\right.$ e $\left.80^{\circ} \mathrm{C}\right)$ por períodos variando de 1 a 10 minutos e com monitoramento da atividade enzimática antes e após cada tratamento.

\subsection{Cinética de inativação}

Os cálculos dos parâmetros cinéticos $\mathrm{D}$ (Tempo de redução decimal), K (Constante de velocidade de inativação), Z (Fator de dependência da temperatura) e Ea (Energia de ativação) foram calculados para a polifenoloxidase e para a peroxidase.

Para o cálculo do tempo de redução decimal (D) e da constante de velocidade de inativação térmica (K) foi utilizado o modelo descrito por Ling e Lung (1978). Para a porção termorresistente foi traçada a curva, conforme Equação 1:

$\log (\% \mathrm{P})=\log \mathrm{K}_{\mathrm{R}} \cdot \mathrm{E}_{\mathrm{RO}} /\left(\mathrm{K}_{\mathrm{L}} \cdot \mathrm{E}_{\mathrm{LO}}\right)+\left(\mathrm{K}_{\mathrm{R}} \cdot \mathrm{E}_{\mathrm{RO}}\right)-\mathrm{K}_{\mathrm{R}} \cdot \mathrm{t} / 2.303$

Simplificada para tempos de aquecimento prolongado, quando:

$\mathrm{e}^{-\mathrm{KL} \cdot \mathrm{t}}$ tende a zero;

$\mathrm{K}_{\mathrm{R}}=$-inclinação $\times 2,303$; e

$\mathrm{D}_{\mathrm{R}}=2,303 / \mathrm{K}_{\mathrm{R}}$.

Para a porção termolábil foi traçada a curva (Equação 2):

$\log (\% \mathrm{P}-\mathrm{A})=\log \mathrm{K}_{\mathrm{L}} \cdot \mathrm{E}_{\mathrm{RO}} /\left(\mathrm{K}_{\mathrm{L}} \cdot \mathrm{E}_{\mathrm{LO}}\right)+\left(\mathrm{K}_{\mathrm{R}} \cdot \mathrm{E}_{\mathrm{RO}}\right)-\mathrm{K}_{\mathrm{L}} \cdot \mathrm{t} / 2,303$

em que, A é dado pela seguinte expressão (Equação 3):

$\mathrm{A}=\mathrm{K}_{\mathrm{R}} \cdot \mathrm{E}_{\mathrm{RO}} /\left(\mathrm{K}_{\mathrm{L}} \cdot \mathrm{E}_{\mathrm{LO}}\right)+\left(\mathrm{K}_{\mathrm{R}} \cdot \mathrm{E}_{\mathrm{RO}}\right)$

O parâmetro A foi obtido graficamente como sendo o valor correspondente ao ponto no qual o prolongamento da curva da fração termorresistente corta o eixo y $[\log (\% \mathrm{P})]$.

$\mathrm{K}_{\mathrm{L}}=$-inclinação $\times 2,303$; e

$\mathrm{D}_{\mathrm{L}}=2,303 / \mathrm{K}_{\mathrm{L}}$.

Para o cálculo do valor de $\mathrm{Z}$ foi traçada uma curva Log D versus a temperatura de inativação térmica das porções termolábil e termorresistente. Este parâmetro é importante para a definição das condições de processamento térmico aplicado na indústria.

A energia de ativação das porções termolábil e termorresistente foi calculada de acordo com Ramaswamy et al. (1989), através da Equação 4:

$\mathrm{E}_{\mathrm{A}}=2,303 \times \mathrm{R} \times \mathrm{T}_{\text {max. }} \times \mathrm{T}_{\text {min. }} / \mathrm{Z}$

A temperatura $\mathrm{T}$ é expressa em $\mathrm{K}$.

\section{Resultados e discussão}

\subsection{Atividade enzimática da POD e PPO}

As maiores atividades enzimáticas observadas foram nos extratos obtidos em $\mathrm{pH}$ 5,5 para a peroxidase e 6,5 para a polifenoloxidase. Os resultados podem ser observados na Tabela 1 , que mostra a média das atividades enzimáticas da POD e da PPO em diferentes $\mathrm{pHs}$ nos comprimentos de onda iguais a 460 e $395 \mathrm{~nm}$, respectivamente. Uma unidade de atividade foi definida como o aumento de uma unidade de absorbância por minuto. $\mathrm{mL}^{-1}$ de amostra.

\subsection{Determinação do teor de minerais e proteína bruta}

Os teores de minerais e proteína bruta encontrados no palmito podem ser observados na Tabela 2 .

Mesmo havendo mudanças com relação ao tipo de solo nas diferentes regiões, os teores de minerais e proteína bruta encontrados estão em concordância com os valores descritos por Araújo (1993), Yuyama et al. (1999) e Monteiro et al. (2002) para o palmito de pupunha.

Tabela 1. Atividade enzimática da POD e da PPO em diferentes pHs.

\begin{tabular}{ccc}
\hline $\mathrm{pH}$ & POD $\Delta \mathrm{DO}_{460 \mathrm{~nm}} / \mathrm{minuto}^{-1} \mathrm{~mL}^{-1}$ & $\mathrm{PPO} \Delta \mathrm{DO}_{395 \mathrm{~nm}} / \mathrm{minuto}^{\mathrm{m} \mathrm{mL}^{-1}}$ \\
\hline 5,5 & 257,2 & 2,54 \\
6,0 & 213,1 & 2,58 \\
6,5 & 142,4 & 3,10 \\
7,0 & 115,0 & 2,82 \\
\hline
\end{tabular}

Tabela 2. Teor de minerais e proteína por $100 \mathrm{~g}$ de palmito de pupunha.

\begin{tabular}{cccc}
\hline Minerais & Proteína $(\mathrm{g})$ & Minerais $(\%)$ & Minerais $\left(\mathrm{mg} \cdot \mathrm{kg}^{-1}\right)$ \\
\hline- & 2,96 & - & - \\
$\mathrm{Mg}$ & - & 0,59 & - \\
$\mathrm{Ca}$ & - & 1,11 & - \\
$\mathrm{K}$ & - & 3,52 & - \\
$\mathrm{P}$ & - & 0,42 & - \\
$\mathrm{Fe}$ & - & - & 10,40 \\
$\mathrm{Cu}$ & - & - & 12,98 \\
$\mathrm{Mn}$ & - & - & 13,57 \\
$\mathrm{Zn}$ & - & - & 73,80 \\
$\mathrm{Na}$ & - & - & 1,44 \\
\hline
\end{tabular}




\subsection{Tratamento térmico da POD e PPO}

Após o tratamento térmico, a POD e a PPO sofreram um decréscimo da atividade, de aproximadamente 70 e $80 \%$, respectivamente, em relação às suas atividades iniciais. As Figuras 1 e 2 mostram a variação da atividade das enzimas em quatro diferentes temperaturas em relação ao tempo, para a POD e para a PPO, respectivamente.

Analisando-se, portanto, a Figura 1, pode-se perceber que houve uma considerável queda da atividade enzimática da peroxidase devido ao aumento do tempo e da temperatura. Obteve-se uma inativação parcial de exatamente $70,68 \%$ à temperatura de $80^{\circ} \mathrm{C}$ e após 10 minutos de tratamento. Não se obteve, no entanto, a inativação total dessa enzima.

Observando-se a Figura 2, nota-se que o decaimento da atividade da polifenoloxidase é bem acentuado, mostrando também que, com o aumento da temperatura e do tempo, houve

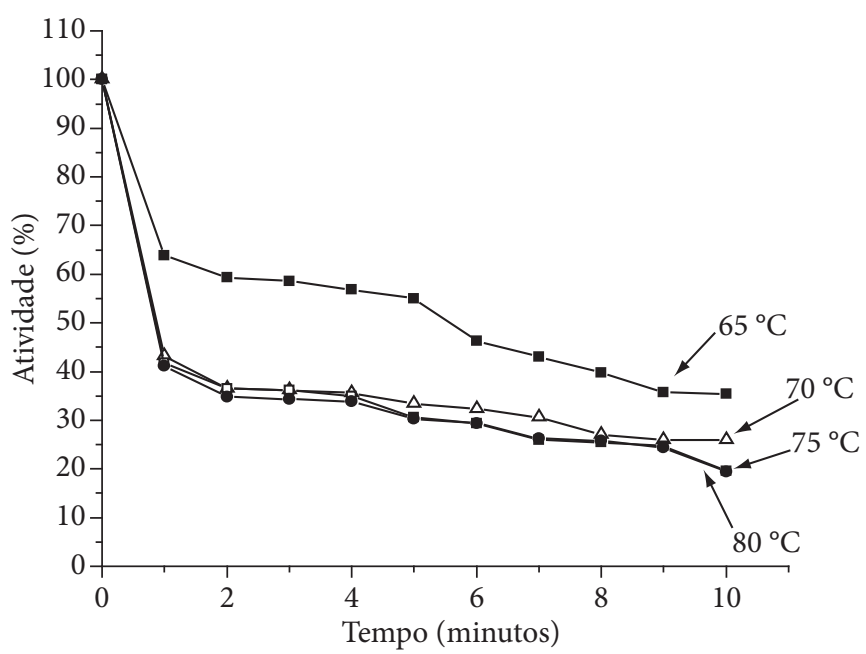

Figura 1. Termoestabilidade da peroxidase (POD) do palmito de pupunha.

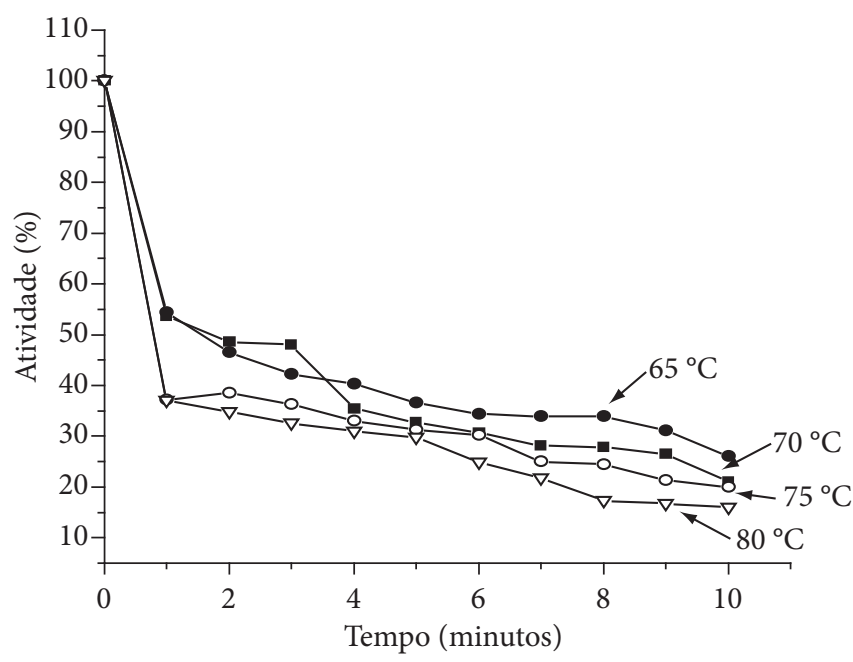

Figura 2. Termoestabilidade da polifenoloxidase (PPO) do palmito de pupunha. uma diminuição bem grande da atividade enzimática, cujo valor determinado aos 10 minutos a $80^{\circ} \mathrm{C}$ foi de exatamente $75,14 \%$ de inativação da PPO.

\subsection{Cinética de inativação}

As curvas de inativação térmica da polifenoloxidase e da peroxidase a $65,70,75$ e $80^{\circ} \mathrm{C}$ apresentaram mudança de inclinação, o que indica a presença de duas porções da enzima, uma termorresistente e outra termolábil. Esta última caracterizada por um tempo de redução decimal maior.

Através dos parâmetros cinéticos (D, K e Z) calculou-se a energia de ativação $\left(E_{A}\right)$ enzimática para as porções termorresistente e termolábil para a POD e para a PPO. Os valores dos parâmetros estão nas Tabelas 3 e 4.

$O$ fator de dependência da temperatura $(Z)$ foi encontrado baseado nos valores dos tempos de redução decimal (D) para as porções termolábil e termorresistente da POD e da PPO para as temperaturas de $65,70,75$ e $80^{\circ} \mathrm{C}$, bem como suas energias de ativação $\left(\mathrm{E}_{\mathrm{a}}\right)$, através dos valores de $\mathrm{Z}$, conforme mostram as Tabelas 5 e 6 , respectivamente.

Os valores da energia de ativação encontrados no presente trabalho, para as porções termolábil e termorresisten-

Tabela 3. Resultados dos testes de inativação térmica da POD no palmito de pupunha a diferentes temperaturas.

\begin{tabular}{crrll}
\hline Temperaturas $\left({ }^{\circ} \mathrm{C}\right)$ & \multicolumn{2}{c}{$\mathrm{D}$ (minutos) } & \multicolumn{2}{c}{$\mathrm{K}\left(\mathrm{min}^{-1}\right)$} \\
\cline { 2 - 5 } & PTL & PTR & PTL & PTR \\
\hline 65 & 24,32 & 24,76 & 0,0947 & 0,093 \\
70 & 16,33 & 13,33 & 0,141 & 0,141 \\
75 & 14,95 & 14,95 & 0,154 & 0,154 \\
80 & 14,86 & 15,05 & 0,155 & 0,153 \\
\hline
\end{tabular}

$\mathrm{PTL}=$ porção termolábil; e PTR = porção termorresistente.

Tabela 4. Resultados dos testes de inativação térmica da PPO no palmito de pupunha a diferentes temperaturas.

\begin{tabular}{ccccc}
\hline Temperaturas $\left({ }^{\circ} \mathrm{C}\right)$ & \multicolumn{2}{c}{$\mathrm{D}$ (minutos) } & \multicolumn{2}{c}{$\mathrm{K}\left(\mathrm{min}^{-1}\right)$} \\
\cline { 2 - 5 } & PTL & PTR & PTL & PTR \\
\hline 65 & 15,56 & 15,56 & 0,148 & 0,148 \\
70 & 13,39 & 13,39 & 0,172 & 0,172 \\
75 & 15,77 & 15,67 & 0,146 & 0,147 \\
80 & 13,63 & 13,63 & 0,169 & 0,169 \\
\hline PTL = porção termolábil; e PTR = porção termorresistente. & \multicolumn{3}{c}{}
\end{tabular}

Tabela 5. Valores de $\mathrm{Z}$ e $\mathrm{E}_{\mathrm{a}}$ das porções termolábil e termorresistente da peroxidase no palmito de pupunha.

\begin{tabular}{ccccc}
\hline \multicolumn{2}{c}{$\mathrm{Z}\left({ }^{\circ} \mathrm{C}\right)$} & & \multicolumn{2}{c}{$\mathrm{E}_{\mathrm{a}}\left(\mathrm{kJ} \cdot \mathrm{mol}^{-1}\right)$} \\
\cline { 1 - 2 } \cline { 4 - 5 } Termolábil & Temorresistente & & Termolábil & Termorresistente \\
\hline 14,84 & 14,93 & & 154,0 & 153,0 \\
\hline
\end{tabular}

Tabela 6. Valores de $\mathrm{Z}$ e $\mathrm{E}_{\mathrm{a}}$ das porções termolábil e termorresistente da polifenoloxidase no palmito de pupunha.

\begin{tabular}{ccccc}
\hline \multicolumn{2}{c}{$\mathrm{Z}\left({ }^{\circ} \mathrm{C}\right)$} & & \multicolumn{2}{c}{$\mathrm{E}_{\mathrm{a}}\left(\mathrm{kJ} \cdot \mathrm{mol}^{-1}\right)$} \\
\cline { 1 - 2 } \cline { 4 - 5 } Termolábil & Temorresistente & & Termolábil & Termorresistente \\
\hline 86,96 & 84,75 & & 26,3 & 27,0 \\
\hline
\end{tabular}


te da peroxidase presente no palmito de pupunha, foram 154,0 e $153,0 \mathrm{~kJ} \cdot \mathrm{mol}^{-1}$, respectivamente, enquanto que os valores encontrados para as porções termolábil e termorresistente da polifenoloxidase foram 26,3 e $27,0 \mathrm{~kJ} \cdot \mathrm{mol}^{-1}$, respectivamente. Os resultados encontrados estão dentro da faixa de energia de ativação reportada para o processo de inativação térmica de enzimas, de acordo com Sgarbieri (1996) e Reed (1975).

\section{Conclusões}

O melhor pH de extração para a peroxidase de palmito de pupunha foi 5,5 e para a polifenoloxidase foi 6,5. No tratamento térmico, aplicado para promover a inativação enzimática tanto da peroxidase quanto da polifenoloxidase, não se obteve a inativação total, indicando a possível existência de isoenzimas termorresistentes. A polifenoloxidase foi menos resistente que a peroxidase. Porém, as energias de ativação estão dentro da faixa de energia de ativação estabelecida para o processo de inativação térmica de enzimas.

Não houve regeneração da atividade enzimática em nenhuma das amostras nas temperaturas estudadas.

\section{Referências bibliográficas}

ARAÚJO, L. M. Aproveitamento industrial e caracterização físicoquímica de palmito de pupunha (Bactris gasipaes H.B.K.). Manaus: INPA/ UFAN, 1993. 50p.

BELEGARD, C. R. G. et al. Avaliação de procedimentos de acidificação de conservas de palmito foliar de pupunha (Bactris gasipaes). Acta Scientiarum Agronomia, v. 27, n. 2, p. 247-245, 2005.

BONACINI, L. A. O mercado de palmito nacional e internacional. In: SEMINÁRIO DO AGRONEGÓCIO PALMITO DE PUPUNHA NA AMAZÔNIA, 1, 1999, Porto Velho. Anais... Porto Velho: Embrapa, p. 15-18, 1999.

CHAIMSOHN, F. P. Cultivo de pupunha e produção de palmito. Viçosa: Aprenda Fácil, 2000. 121p.

Desenvolvimento de pupunha (Bactris gasipaes Kunth) cultivada em diferentes regiões do Paraná. Boletim Técnico, (Instituto Agronômico do Paraná - Iapar), v. 67, p. 1-54, 2002.

CLEMENT, C. R.; BOVI, M. L. A. Novos mercados de palmito minimamente processado e "pronto-para-uso". In: SEMINÁRIO DO AGRONEGÓCIO PALMITO DE PUPUNHA NA AMAZÔNIA, 1, 1999, Porto Velho. Anais... Porto Velho: Embrapa, p. 15-18, 1999.

CLEMENT, C. R.; MORA URPÍ, J. Pejibaye palm (Bactris gasipaes, Arecaceae): multi-use potentioal for the lowland humid tropics. Economic Botany, v. 41, n. 2, p. 302-311, 1987.

CLEMENTE, E. Purification and thermostability of purified isoperoxidases from oranges. Phytochemistry, v. 49, n. 1, p. 29-36, 1998.
CLEMENTE, E.; PASTORE, G. M. Peroxidase and polyphenoloxidase, the importance for food technology. Boletim da SBCTA, v. 32, n. 2, p. 167-171, 1998.

FERREIRA, V. L. P. et al. Comparação entre os palmitos de Guilielma gasipaes Bailey (pupunha) e Euterpe edulis Mart. (juçara). I. Avaliações físicas, organolépticas e bioquímicas. Coletânea do Instituto de Tecnologia dos Alimentos, v. 2, n. 2, p. 255-272, 1982a.

FERREIRA, V. L. P. et al. Comparação entre os palmitos de Guilielma gasipaes Bailey (pupunha) e Euterpes edulis Mart. (juçara). II. Avaliações físicas e químicas. Coletânea do Instituto de Tecnologia dos Alimentos, v. 12, n. 1, p. 273-282, 1982b.

JIMENEZ, E. Evaluación de alternativas tecnológicas para $1^{\mathrm{a}}$ conservación del palmito de pejibaye como producto fresco. Corbana, v. 16, n. 38, p. 34-40, 1992.

KAPP, E. A. et al. Tempo de preservação de tolete de palmito pupunha (Bactris gasipaes) minimamente processado e armazenado sob refrigeração. Publicatio, Ponta Grossa, v. 9, n. 3, p. 51-57, 2003.

LING, A. C.; LUNG, D. B. Determining Kinetics parameters for thermal inactivation of heat resistant and heat labile isoenzymes from thermal destruction curves. Journal of Food Science, v. 43, n. 4, p. 1307-1310, 1978.

MCLELLAN, K. M.; ROBINSON, D. S. Heat stability of peroxidase from orange. Food Chemistry, v. 13, n. 4, p. 139-147, 1984.

MONTEIRO, M. A. M. et al. Estudo químico de alimentos formulados à base de palmito Bactris gasipaes H. B. K. (pupunha) desidratado. Ciência e Tecnologia de Alimentos, v. 22, n. 3, p. 211-215, 2002.

RAMASWAMY, H. S.; VAN DE VOORT, F. R.; GHAZADA, S. An analysis of TDT and Arrhenius methods for handling process and kinetic data. Journal of Food Science, v. 54, n. 5, p. 1322-1326, 1989.

RAUPP, D. S. et al. Conservas de palmito de pupunha em diferentes salmouras-avaliação sensorial. Publicatio, v. 10, n. 1, p. 27-33, 2004.

REED, G. Enzymes in Food Processing. New York: Academic Press, 1975.

SGARBIERI, V. C. Proteína em alimentos protéicos: propriedades, degradações, modificações. São Paulo: Varela, 1996.

SIDDIQ, M.; SINHA, N. K.; CASH, J. N. Characterization of polyphenoloxidase from stanley plums. Journal of Food Science, v. 57, n. 5, p. 1177-1179, 1992.

SOARES, A. G. Palmito de pupunha - alternativas de processamento. Horticultura Brasileira (Suplemento), v. 15, p. 198-199, 1997.

TONET, R. M; FERREIRA, L. G. S.; OTOBONI, J. L. M. A cultura da pupunha. Boletim Técnico n. 237. Campinas: Coordenadoria de Assistência Técnica Integral (CATI), 1999. 44 p.

YUYAMA, L. K. O. et al. Determinação de elementos essenciais e não essenciais de pupunheira. Horticultura Brasileira, v. 17, n. 2, p. 91-95, 1999. 